Volume: 11 Issue: 2 Year: 2014

\title{
On the beauty of nature, paintings and music
}

\author{
Ekin Çoraklı ${ }^{1}$
}

\begin{abstract}
There is a wide range of things that are classified by humans in terms of their level of beauty. The word 'beautiful' is used to define some of the natural entities living and nonliving, unnatural objects or ideas produced by humans, and the works of art, which are unique products of human hand and brain. Beauty, as a concept awakening a common feeling of pleasure, may mean something deeper than we are aware of. This meaning is perhaps hidden in its deeper aspects, which we have to give effort to analyze. Hence, within context of this paper, common and specific properties of the beauty of nature, paintings and music will be discussed. In addition, the stages of the perception of the beauty of all kinds will be called into question, and an account about the process of the judgment of beauty will be suggested. The specific types of beauty analyzed through the paper are limited with the beauty of nature, paintings and absolute music (music without words), following an opening remark about the beauty in general.
\end{abstract}

Keywords: Beauty, beauty of music, beauty of paintings, natural beauty, beauty of arts, judgment of beauty.

\section{Introduction}

Perceiving the beauty of something is an activity, which requires both a subject to perceive and an object to be perceived, and which ends with an aroused feeling with a range between being delightful and non delightful. While Leibniz (1700) puts emphasis on mere feelings on the perception of beauty and considers the source of this perception as unobservable, the succeeding philosopher Kant (1790) gives role to also understanding, which works in a harmonious yet indeterminate play with imagination in the judgment of beauty. As a result of this unique process, which depends on feelings but also includes the participation of understanding and imagination as mentioned above, a universal yet neither objective nor solely subjective judgment is born. The conclusion Kant have reached helps us receive at least a tentative answer to the question of, as he mentions himself as well, why all of us expect from the other to make the same judgment towards

\footnotetext{
${ }^{1}$ Research Assistant Dr., Abant Izzet Baysal University Music Education Department, ekincorakli@gmail.com
} 
Çoraklı, E. (2014). On the beauty of nature, paintings and music. International Journal of Human Sciences, 11(2), $297-313$. doi: $\underline{10.14687 / \text { ijhs.v11i2.2900 }}$

an encountered beauty, and motives us to make an account of beauty, by considering it as a concept having universal aspects albeit not having strict borders.

There are two clear facts about the perception of beauty: It is perceived by at least one of the sense organs and gives pleasure when it is perceived. In other words, after we perceive the beauty of an entity, which depends on its properties we see, hear, smell, taste and touch, we have the feeling 'pleasure'. Here, it has to be emphasized that we might not use all of our sensual capacities while judging a specific kind of beauty, i.e. we might use all of our sense organs in perceiving the natural beauties, though we merely use our visual and audial capacities while judging the beauty of the art works, whether separately or together.

Seeing, which has a more direct impact on our perception of things, is followed after the other senses respectively hearing in the case of judging all kinds of beauties and smelling, tasting and feeling of touch in the case of judging the beauty of nature. In many examples, the beauty of the object depends on only one sensual property of it, like in the case of a musical work or a perfume. However, in some cases, we attribute the beauty of the object to an only one sensual property of it (which is usually the visual property of it), by missing out the effect of the other sense. The beauty of many natural entities do also belong their audial, tactual and olfactory properties with the visual ones they have, i.e. the beauty of a flower, a bird or sea. Perhaps we make a mistake in attributing the beauty to the mere object in our statements, which arouses only one sensual property of it in our minds, though there may be more sensual properties having impact on its beauty. Thus, instead of the statement ' $\mathrm{x}$ is beautiful', the statement such as 'the $\mathrm{y}$ (sensual property) of $\mathrm{x}$ is beautiful' could be more appropriate for describing our perception of beauty in a more detailed and clear way.

In brief, the beauty, which is the result of a unique kind of universal judgment, gives us pleasure and lies on the properties of the entities primarily perceived by our sense organs. Now, it is time to discuss what these properties are. But before starting, it has to be stated that while it is the same word 'beauty' we are using to qualify a wide range of entities, we call these things as beautiful not due to the same properties they have got. Therefore, a natural entity, a work of painting or a musical work may owe their beauty to different properties of them. Hence, I will first discuss the common properties of things causing us to deem them as beautiful, and then continue with other separate chapters, in which I shall deepen on different kind of beauties of different kind of entities.

All of the things we assess in terms of their beauty have a certain volume in life and a form in our perception, in accordance with their properties from which we sense the beauty. Visual forms are more noticeable to perceive thanks to the directness of visual perception, while audial forms are measured in terms of their extension, strength and intensity. The form of the smell and taste is more ambiguous to be recognized and measured by their strength and intensity. The form of the 
Çoraklı, E. (2014). On the beauty of nature, paintings and music. International Journal of Human Sciences, 11(2), 297-313. doi: $10.14687 /$ ijhs.v11i2.2900

feeling of touch depends on the touched object's degree of some physical qualities such as shape, softness and heat.

There is something in forms of some entities, which arouses the feeling of beauty in us. That something is harmony, taking its foundation from balance. Leibniz (1700), though not reflecting exactly the same idea, states that in sound and also touch, taste and smell, the sweetness includes a kind of order, which is complemented with harmony and constitutes the 'beauty'. Balance, as the precondition of the harmony, should be present in the general form, i.e. not being too big, small, loud, silent, simple, detailed etc., in the elements constituting the general form and between the general form and sub-formal elements. Harmony, then, is being realized and recognized in the elements constituting the form, such as sub-shapes and the transition of sub shapes between themselves and to the general form. This system works in such a perfectly fluent way that the beholder perceives all these 'form' events in a little while and judges the entity in terms of its beauty. Hence, as the result of these formal qualities, the entities we regard as beautiful catch our interest at first perception by their being different from ordinary examples.

There is an important question to be asked at this point. Can formalism provide sufficient explanation for the beauty as a whole? Is there something beyond senses, which needs to be scrutinized in the process of seeking the source of this attraction, mist, or magic on these objects? It can be claimed without controversy that harmony and balance in the formal qualities of an image of a tree natural or depicted, a sound of the birds singing or a symphony, as well as the smell of an object, the taste of a food or the texture of an object have a primary role on our judgment of beauty. However, attributing the beauty to only formal elements of the entities seems to end the pursuit to reach a deeper understanding of the aesthetic judgment. Thus, I will continue with other aspects of the general beauty, depending on my own perspective of the beauty, which I hope will provide support and inspiration for us to use a new way of thinking.

It is definite that we feel pleasure as soon as we perceive the beauty of an entity. By then, does this feeling fly away immediately? I think the answer is negative. To fulfill the complete judgment of the beauty, two more feelings should arouse following the pleasure: Appreciation and peace. After we get the instantaneous aesthetic delight, our brain strives to reach to an appreciation, as a continuation of it. In this process, which is a stage between seeing the object at first sight and conceiving it as a whole ${ }^{2}$, the source of this beauty is unconsciously questioned, which consequently leads the beholder to feel admiration to the creator and how it reaches this miraculous achievement. In the natural beauty, we admire the miracle of the great power of nature, whereas in fine arts, we attribute our appreciation to the unbelievable skills of the artist, which we think is the source of beauty

\footnotetext{
${ }^{2}$ In Kantian terms, 'understanding the concept of the object'
} 
Çoraklı, E. (2014). On the beauty of nature, paintings and music. International Journal of Human Sciences, 11(2), $297-313$. doi: $10.14687 /$ ijhs.v11i2.2900

causing the pure delight inside us. This appreciation inspires us to think more profoundly about the circle of life and the power of humans, as this kind of pure pleasure is beyond all terrestrial explanations and keeps its mystery. These deep feelings and ideas bring the beholder to the final stage of the judgment of beauty, which is the feeling of peace. Natural beauties by reminding us the continuous circle of life, paintings by capturing an ordinary moment from this endless circle and transferring it into something beautiful and eternal, and music, with a delicate manner, by reflecting the energy and flow of this endless circle causes us to reach this highest stage. Some of us, indeed, feel this kind of peace after this judgment, which makes us move away from the empirical world full of conflict and reaches us to a stage, which we feel and think about our existence. Isn't this what some of us feel after listening to Beethoven's pastoral symphony, experiencing the exhibition of Matisse or have time in a garden full of flowers and trees?

Briefly, the pleasure is felt towards the beautiful object, though this delight transfers into an appreciation towards the source of this beauty and a final feeling of peace. In other words, aesthetic judgment is the effort of the delight to reach the stage of appreciation and peace to follow after the first perception. If it cannot fulfill all these stages, it misses its value and is therefore incomplete.

Then, as the result of this perspective, these stages have already been there, inside the beauty, waiting people to be realized, and perceiving the beauty is actually like food for people's restless soul. This food is not like the regular food people have to eat in order to survive, yet a food for them to live with having more awareness. The problem aroused here is, most people do not realize this benefit of the beauty, as it is not the result of a primary need. They usually pass by beauties without even feeling the pleasure, or even if they take the pleasure from the beauty, this pleasure disappears like the light of fireworks fade away immediately after existing for a restricted moment. Is this awareness due to the capacities, which are not evoked in some people? If yes, how and why? This is a very difficult issue to find definite solutions. And perhaps, the answer lies on the unexplainable part of the attraction of the beauty, which is somewhere in the unconscious state of mind, beyond the world of space, time and causality where the formal qualities belong. Let's continue with other chapters and discuss the beauty of different types of entities, and then, return to the same discussion in the following chapters, taking support from the new ideas collected.

Both Lessing (1853) and Hanslick (1891) stress the importance to examine unique qualities of different kinds of arts, the former aesthetician referring to painting and poetry, and the latter to music. Not only to understand the artistic beauty, but also to understand all types of beauty, we strongly need to discuss the unique qualities constituting the beauty of different entities. Hence, to realize this aim, the beauty of natural entities, painting and music will be respectively scrutinized. 
Çoraklı, E. (2014). On the beauty of nature, paintings and music. International Journal of Human Sciences, 11(2), $297-313$. doi: $10.14687 /$ ijhs.v11i2.2900

\section{Beauty of living and nonliving entities constituting the nature}

In the nature, living entities such as animals, plants and humans or nonliving ones such as mountains, sea or objects in the sky can be called as beautiful. Many artists have received inspiration from the nature. Thus, the works of literal and visual arts are full of illustrations of nature. In order to have an understanding of why we deem these entities as beautiful, we have to spend some effort to analyze (1) the qualities of beauties in nature distinguished from the beauty of arts, and (2) the distinctive qualities of the beauty of natural entities classified as landscapes (including plants) and animals.

To begin with, all of the entities considered as beautiful, except for natural ones, have been shaped by humans, while natural beauties have the advantage of being natural. They don't have any artificial feature enclosed, thus, they are pure and spontaneous. This kind of independent beauty causes the natural objects intrinsically have the harmony and balance in the forms. A flower, for instance, doesn't need any other features than it inherently possesses, it already has a lively color, an elegant shape, a unique smell and a tender texture.

Natural entities, also, possess the liveliness in formal qualities due to being in a natural environment. Sunlight provides a powerful support to the beauty of many entities living and nonliving, while the moonlight and stars achieve the same task at night. A fish reveals its entire beauty in the magical atmosphere of the sea. Many elements in the natural environment such as the mist, the snow, the natural sounds or smells contribute to the occurrence of the beauty.

Another unique quality the natural beauties possess compared to beauty of arts is their addressing all the sense organs of the humans. We can find a flower beautiful not only because of merely its visual qualities like its shape and color, but also because of its pleasurable smell and its giving a soft and refreshing feeling when we touch it. The beauty of the sea lies on its unique blue tone, which unites with the sound of waves and the smell of the seaweeds; likewise, a bird is beautiful because it is visually, audially and tactually attracting. The nature, therefore, presents a rich content of qualities charming all the senses, which creates an advantage for it to be regarded as beautiful.

There might be other properties of nature that makes its beauty unique besides the ones mentioned above. This is a truth that humans and other natural entities are parts of the same environment constituting this continuous circle. This truth leads to think about a possibility that the judgment of beauty is a natural result of being a both natural and living entity. The only difference of the humans from the other living entities is having intellectual capacities, which causes them to make a judgment of beauty and put this judgment into words. Thus, the nature with all its sensual capacities reflects a familiarity with humans, because of which the humans instinctively find 
Çoraklı, E. (2014). On the beauty of nature, paintings and music. International Journal of Human Sciences, 11(2), $297-313$. doi: $\underline{10.14687 / \text { ijhs.v11i2.2900 }}$

themselves in judging its beauty. Perhaps, it is the answer of why humans have tendency to perceive the beauty of natural things more immediately than the examples of art.

Even though natural objects are strong candidates to be judged as beautiful, not the entire population of the nature possesses beauty. Then, which entities in the nature reach the stage of being beautiful? Schopenhauer (1819) gives the first rank to landscapes, which, he thinks, reflects the universal truth and consistency of the nature. It is beyond controversy that landscapes and many components generating the landscapes in the nature are appropriate candidates for being beautiful, such as the sky possessing countless tones of colors with the accompaniment of sun light and clouds, or the forest, as well, with many colors, which unites with the fresh feeling of wind and birds singing. However, there are also landscapes, which do not arouse any aesthetic pleasure in us. Consider a garden full of faded flowers, a brook starting to run dry, or a prairie facing the draught. They have lost their liveliness, which makes them being lack of the formal beauty the nature endows them, i.e. the richness of the shapes or the liveliness of colors. There are also cases in nature, when the entity is still alive, but have lost its formal integrity, therefore its beauty; because of natural or unnatural reasons, such as in the case of a tree whose branches and leaves are damaged or missing. In some cases, the beauty is ruined because of unnatural effects either external or internal. The sea with having wastes on its surface is an example for the former case, and the felt grief instead of pleasure towards a specific kind of flower, which reminds sad memories, is an example of the latter one.

Though Schopenhauer (1819) considers the entities constituting the animal world as less naive than the non-living entities in the nature due to their determined forms and possessing external aims and ends, the animals, as well, possess a strong potential to be called as beautiful. There are several kinds of animals, i.e. birds or fish, which arouse in us the feeling of beauty with their colorful fur/skin and anatomic shape. Also, as humans, we possess the probability of being beautiful, which is considered to be the main reason of passionate love and has created inspiration for many poets and writers. However, like the landscapes, entities constituting the animal world having the beauty of this kind, is a group limited in number. When we try to find out the distinction of the beautiful entities in the animal world compared with the non-beautiful ones, we encounter the formal qualities, as in the case of landscapes, because of both similar and different reasons. Like the plants, which are elements of landscapes, animals receive the power of their beauty from their health; thus an ill or dead animal loses its probability to be beautiful. However, there are also some cases that while some animals are already healthy, we still cannot find any beauty in them. The reasons we find a sparrow beautiful, but not a cockroach depends on both formal reasons again, i.e. the latter being tactually and visually irritant due to the degree of heat in its body, hardness of its 
Çoraklı, E. (2014). On the beauty of nature, paintings and music. International Journal of Human Sciences, 11(2), $297-313$. doi: $10.14687 /$ ijhs.v11i2.2900

skin or lack of richness in color. External or internal effects, like in the case of landscapes, i.e. causing fear before reaching to pleasure also step in the aesthetic judgment of these entities. The proof for the latter effect also lies on the answer why we find domestic cats more beautiful than wild cats. Domestic cats are safer to touch (at least most of them), therefore do not trigger any kind of apprehension as we experience while looking at wild cats. A person's beauty lies on formal reasons as well, i.e. the harmony and balance of the organs with the whole body or liveliness of the skin. If we look at the humans from the perspective that they also have soul together with their body, the formal beauties take support from also the indicators of a good soul, such as sincere looking eyes and a honest smile.

I have tried so far to examine the beauty of nature in terms of its unique qualities compared with other kinds of beauty and among its own components. As it seen, these qualities are formal, even if the reasons take their source from the distinctive qualities of the nature. Is it an adequate inference that the beauty of nature owes its beauty merely to the formal elements, which are belonging to the empirical world in which we are using our senses? What is happening in our minds in the process of judging the beautiful, and may this process have more importance in our lives than we have realized? This paragraph of Kant (1790) seems to prove that he had anticipated the problem in the incomplete examination of the aesthetic judgment and thinks of a connection between taste and moral feeling:

'Taste is, in the ultimate analysis, a faculty that judges of the rendering of moral ideas in terms of senses (through the intervention of a certain analogy in our reflection on both); and it is this rendering also, and the increased receptivity, founded upon it, for the feeling which these ideas evoke (termed moral sense), that are the origin of that pleasure which taste declares valid for mankind in general and not merely for the private feeling of each individual. This makes it clear that the true propaedeutic for laying the foundations of taste is the development of moral ideas and the culture of the moral feeling. For only when sensibility is brought into harmony with moral feeling can genuine taste assume a definite unchangeable form.' (p.183)

I think, there is a mistake that we making while scrutinizing the beauty: It is that, we consider the judgment of beauty as something merely giving pleasure and skipping other probable stages; or with a slightly different perspective, we ignore the deeper aspects of aesthetic pleasure, which is unquestioningly the primary feeling aroused in the aesthetic judgment. Aesthetic pleasure gains its value from its very unique quality that it has not taken its origin from the endless ambitions of humans. On the contrary, through the experience of this judgment, humans show a calm receptiveness instead of feeling the desire to win the beautiful object. This judgment, therefore, has 
Çoraklı, E. (2014). On the beauty of nature, paintings and music. International Journal of Human Sciences, 11(2), $297-313$. doi: $\underline{10.14687 / \text { ijhs.v11i2.2900 }}$

a pure quality on our perception, without the effects of external and worldly reasons, reflecting the innocence of the humanity, which humans have in their inside but somehow lost.

Let's look at this issue in terms of the beauty of the nature. Assume that while sitting in a park, we are impressed by the beauty of a tree. Would it be enough if we merely have the feeling of delight after our judgment on it? My answer is 'no'. According to the ideal perception of beauty, at first, a pleasure is felt towards this entity, whose elements exhibit great harmony and balance with its attracting shape and lively color spectrum. Then, this pleasure makes its way towards the appreciation of power of the nature and the beholder feels admiration to this great power for causing this genuine pleasure in him. This feeling, finally, makes him realize the eternality of this continuous circle and brings him the feeling of peace. The beholder in the park, then, is awakened in a way. The beauty has brought him somewhere beyond ordinary life, to a world of pure feelings and ideas about life.

The important point as mentioned also in the first chapter is, these stages are not for only special people to complete. On the contrary, it is waiting there to be experienced by the whole humanity, yet requiring a partially unconscious mind refined from all external aspects. It is odd that to reach pureness, which is the simplest form of living, humans have to give too much effort. This, perhaps, is the main reason of the problems humanity is inevitably facing.

This kind of a perspective may be criticized by attributing too much role to the judgment of beauty. However, when the analysis of the beauty of paintings and music is completed, I believe, a more reliable basis for this account will be provided.

\section{Beauty of the works of painting and music}

Even if each of these arts is unique in several aspects, they also have many qualities in common because of being a fine art. These qualities make the aroused feelings after the judgment possess dimensions in common. Then, it will be better to start the analysis from these common qualities, and then discuss the distinctive qualities of painting and music.

The most significant property of the works of music and painting is, as that of all fine arts, the beauty is intended, though the beauty of the nature, as mentioned in the previous chapter, is spontaneous. The works of art are products of the physical and mental efforts of the artist, which he combines his talent with. While a composer or a painter is constructing his work, he spends time and effort with thinking, imagining, writing, modifying and else, until he accomplishes the final-best version. These endeavors end with a purely beautiful product, which is perceived fluently at first sight or hearing, without revealing the stages of the spent effort. This perception, as that in the natural beauty, is followed after an immediate feeling of delight. 
Çoraklı, E. (2014). On the beauty of nature, paintings and music. International Journal of Human Sciences, 11(2), 297-313. doi: $10.14687 /$ ijhs.v11i2.2900

My account about the other stages occurring in the judging the beauty works more clearly with the judgment of the beauty of arts. Thus, the beauty of the works of art has to be measured also with their artistic value, which is the result of the fact that the creation process of fine arts requires intellectual and imaginative processes, and causes to reach the stage appreciation in a natural motion. Artistic value includes the technic and stylistic properties of the work of art, finalized with a necessary aspect: uniqueness. As the result of the pursuit for uniqueness, the beauty of art has gained new dimensions through the history, on the contrary of the beauty of nature, which reveals a stable character. When we look at the first paintings, we see that the aim is merely to reflect the natural beauties. However, in parallel with the improvements in the civilization, all fine arts came to a point to seek for originality, which finally became a necessary condition for being a fine art. The traditions, such as baroque, classical and romantic appeared in music and painting, can be considered as the result of this very nature of the fine arts. An important point has to be emphasized in here: These changes have extended the area of being artistically beautiful, instead of rejecting the beauty of the past traditions. Thus, Vinci's Mona Lisa or Handel's Water Music is still regarded as beautiful, despite the newborn trends following them. An ideal art lover, then, putting his intellectual capacities on this judgment, examines the work in terms of its including technic fundamentals, which helps to create a visual or audial shape of harmony and balance, innovative usage of these fundamentals and finally having a unique style, which depends on the creative skills of the artist, and does not give his credit for merely its sensual properties perceived immediately. The appreciation, as mentioned in the previous chapters, is directed towards the talent of the artist right after the artistic properties are recognized.

This property of the aesthetic judgment of art also contributes to the reason why we find some ordinary scenes depicted in the painting beautiful. We do not have the feeling of delight and appreciation towards people playing with cards in real life, but we definitely do it while looking at Cezanne's Card Players, because the felt feeling of beauty depends also on the artistic qualities of the painting. The judgment of the beauty of music, likewise, requires intellect to step in. Hanslick (1891) is quite determined that the aesthetic judgment of music will not be completed without reaching a mental pleasure. A careful listener, indeed, recognizes many artistic qualities such as the development of the theme, the counter theme and their appearing many times in a similar or different way through the piece, or changes in the dynamics such as pitch, tempo and strength, all of which contributes to his appreciation of the beauty in the music. Or perhaps, as Kivy (2002) suggests, the listener even plays intellectual plays such as hypothesis game and hide and seek ${ }^{3}$.

\footnotetext{
${ }^{3}$ Hypothesis game includes getting results of the hypotheses about the coming musical events and bide and seek includes recognizing the themes when they occur.
} 
Çoraklı, E. (2014). On the beauty of nature, paintings and music. International Journal of Human Sciences, 11(2), $297-313$. doi: $\underline{10.14687 / \text { ijhs.v11i2.2900 }}$

Although this process has more aspects beyond the intellectual ones (that will be discussed in the following paragraphs), we should be mentally aware of the artistic properties of music in order to reach a complete feeling of beauty.

There are distinctive qualities of paintings and music, which should be emphasized before discussing the third stage of the judgment of artistic beauty. First is the very difference of the perception process of these fine arts. Music is a continuous process, having a beginning, development and end, which proceeds for a certain time designated by the composer. Hence, it does not let the listener perceive it freely, as in the perceiving process of painting. If the duration of the musical piece is for 9 minutes, all the audiences complete the hearing of it in 9 minutes. In the process of perceiving the artistic beauty of paintings, though, there is a chance for the beholder to determine the examining process of the work. This situation does not prevent the fact that both a beautiful work of painting and music attracts at the first perception (in the pleasure stage), induces the feeling of appreciation in the process of examining of the artistic qualities and finally awakens the feeling of peace. However, because the sound of music fades away after the listening process, unlike the painting, which always stands there waiting to be judged, the pleasure may not reach to a complete appreciation and peace. In other words, the nature of the painting permits the beholder to examine all details repetitively and internalize them, while the music's independent flow may block the complete aesthetic judgment of the work. As a result, the experience of the music listening may require repetition, in order to reach the highest stage of its aesthetic judgment. This is perhaps, whether consciously or unconsciously, felt by the composers and caused them to use many repetitions in their works.

The second point, which gives rise to the arguments about the beauty of both painting and music is the representational aspects of these arts. It is a recognized fact that painting (except for the abstract ones without a title) is a representational art, however this does not mean that its mere purpose is to represent objects or ideas. It uses these representations to reach to the beauty, which is the main aim of all the arts. Further, the beauty of the painting does not lie on the beauty of the object represented, though that beauty may contribute to the delight in the first stage of the judgment. If it were, then there would be no answer why we find many depictions of ordinary women beautiful when depicted in painting. The depiction of 'Mona Lisa' by Vinci and 'Madam Matisse' by Matisse owe their beauty to their brilliant technique and unique style, instead of the beauty of the models. 'Card Players' by Cezanne (aforementioned above) and 'The Onions' by Renoir also prove that the represented scene is not the case in the beauty of painting. Even scary scenes transfer into beauty, when touched by the hand of an artist, such as 'David with the Head of Goliath' by Caravaggio and 'Hunting Birds at Night' by Millet. The motivation for attending an 
Çoraklı, E. (2014). On the beauty of nature, paintings and music. International Journal of Human Sciences, 11(2), 297-313. doi: $10.14687 /$ ijhs.v11i2.2900

exhibition, thus, is not to see beautiful objects, but beautifully represented objects. If the aim were the former one, the place to go would be a place where we could find the real and live version of the depicted object, instead of an exhibition.

Sometimes, by using depictions, painters portray a nonvisual thing, like a sound or a feeling, i.e. Munch's famous depiction 'Scream' and Henner's 'Solitude'. In these cases, there are two things to be considered as important: First is, the title helps the perceiver to understand what has inspired the artist and to recognize the idea lying beneath the object seen in the depiction. Second is, the title helps to recognize the reasons of some details, which the perceiver has difficulty to give a meaning. Knowing that the man's holding his ears is because of a scream helps us to complete the arranged fiction of the painting. However, being aware of the underlying idea of the painting does not change the fact that the aesthetic judgment depends on primarily the artistic qualities of the work, which include artistically innovative ideas instead of the innovative ideas that we encounter in the real world. While in looking at a real tree, standing lonely in a field, we may have the same feeling that this tree is the symbol of loneliness. Thus, a work abounded with higher quality in artistic aspects yet lack of an underlying idea can still be beautiful, whereas a merely innovative work of painting full of innovative ideas yet lack of artistic qualities cannot give the feeling of the beauty. The latter type of a work can only contribute the unaesthetic aspects of the work, such its being interesting, different or witty. Therefore, the appreciation process of the perceiving the beauty of a painting is enriched with the contribution of the underlying idea of depicting a nonphysical thing, whereas the artistic ideas reflected in the painting are having more significant impact on the judgment of the beauty of a painting.

When it comes to analyze abstract painting, it will make more sense to classify them as the ones with a title and the ones, which are purely abstract. The title in the abstract paintings have also a significant role while they are being aesthetically judged, since they provide the understanding about what the painter is using as a representation. It is nearly impossible to grasp that Malevich uses a girl as a representation in his painting 'Peasant Girl', unless we are aware of the title. Like in the case of paintings depicting a nonphysical thing, also in this case, the title helps to fill in the gap in the understanding of the fictional side of the painting. Furthermore, the discovery of the invisible or sometimes hidden thing in the painting will contribute to the aesthetic judgment by providing chance to examine the technique deeply. However, examining the artistic qualities, as in all the types of paintings, have the first rank in the judgment of the beauty of paintings.

There is a last different kind of painting, which is distinguished from all the examples. It is abstract painting without a title, or with a title not telling what it depicts, because there is anything it aims at to represent. These works give no clue about what it is about and merely consists of purely 
Çorakl1, E. (2014). On the beauty of nature, paintings and music. International Journal of Human Sciences, 11(2), $297-313$. doi: $10.14687 /$ ijhs.v11i2.2900

artistic qualities. What we see in Kandinsky's 'Composition 4' is merely ambiguous shapes and glittering colors at first sight, yet giving an immediate pleasure. While we continue to examine it in terms of its aesthetic qualities, we realize the mastery about how some figures depicted with a different style and colors used in a distinctive way. Even though, we are not still sure what is depicted and sometimes constitute our own story from the unclearness. This mystery, which unites with a great artistic style, attracts our feelings. The view of even regarding a blank paper or a spontaneous touch of a brush as fine art is what my account of beauty cannot accept. Hence, according to my account, interesting or innovative ideas, which exclude the artistic aspects, do not contribute to the feeling of any kind of beauty.

Whether absolute music has the capacity to represent anything is being discussed through the history of philosophy of music, mainly because of the emotions aroused in the music listening process. After centuries of the discussion process, the belief that puts emphasis on emotions in designating music's content in the early times (Plato and Aristotle) transferred into the notion that music's meaning depends on mostly tonal events. The existence of emotions is not denied and is considered as pathological, resemblance based, one of the elements of music or metaphorical (Hanslick, 1891; Budd, 1995; Kivy, 2002; Scruton, 1997; Peacocke, 2009).

It is certain that, unlike paintings, music is usually not using any physical or spiritual object to represent (except for the examples of programmed music, which have a title or a literal concept). Hence, music literature is full of untitled concertos, sonatas, preludes and so on. While listening any of symphonies of Brahms, we do not restrict our selves to find or examine a depicted thing or an idea, but merely focus on flowing sound events. We certainly may have dreams, ideas or feelings about our own lives while listening to music, but all these belong to our private experience and are beyond the universal beauty of the music.

The case of programmed music is more complex to analyze. It is an inevitable fact that the title or text helps the listener to grasp the intended parallelism between those and music. However, a passionate music listener will probably still receive primarily the independent beauty of music, which is beyond all representations. For instance, in some passages of Beethoven's 6th symphony, the knowledge about the content helps us to understand the reason of some unexpected sound events, i.e. the violoncellos tensely accompanying the calm theme, which aims to depict the last claps of thunder in the ending of the storm. On the other hand, it would probably give the same feeling of the beauty as his other untitled symphonies like the 4th or 7th, if we didn't know its content. The problem is, music, as a process, has analogy with lots of concepts, such as life itself, actions, natural events, speeches and so on, which are also processes including a beginning, a development and an end. If we would like to add a content, say, into Bach's Chaconne for violin, 
Çoraklı, E. (2014). On the beauty of nature, paintings and music. International Journal of Human Sciences, 11(2), 297-313. doi: $10.14687 /$ ijhs.v11i2.2900

we can title it as 'desperate remonstrance after a lost love' and no one may claim that this title have less relevant parallelism with its melody than that of the 'Morning Mood' in the orchestral suit of Peer Gynt by Grieg. Moreover, 'Morning Mood' could have many alternative titles or actually would not need any title. If the composer did not give any title to it, it would not lose a bit of its musical merit. ${ }^{4}$

There is one more interesting dimension in the case of programmed music. Activities appealing to multiple sensual inclinations create a more common interest towards that activity. For instance, the main reason why there is much more people in movie theatres than in the classical music concerts or exhibitions is cinema uses visual (the moving photographs), literary (the text) and audial (film music) content. It works for lots of people, who have different sensual aptitudes, and, therefore, who have tendency to participate in different types of engagements. Hence, the text supporting a musical piece would cause an interest for also people who are inclined to engage with literary activities. The same result occurs in the paintings, which uses depictions to describe a nonphysical thing. The fiction, like in the case of programmed music, steps in the process of perception, however does not contribute to the independent artistic qualities of the works.

In sum, representations are mostly used and needed in paintings to judge their beauty, however they are only means instead of being the aim. In addition, the reason of a painting to give the feeling of beauty is not the underlying innovative ideas that we can see encounter in real world, but artistically innovative ideas. Then, the beauty of the paintings are in their artistic qualities, including technic fundamentals which requires mastery in the usage of colors, tones, lines, perspective creating a visual shape of harmony and balance, innovative usage of these fundamentals and finally having a unique style.

In music, the representations are mostly not used, and the listener is left with only pure sound events. The judgment is done, just like in the case of paintings, due to the artistic qualities of the work, including technic qualities such as mastery in cumulating separate sounds with a meaningful order and the usage of the dynamics, creating an audial shape of harmony and balance, innovative usage of the dynamics and finally having a unique style.

We are now ready to analyze the judgment of beauty in terms of the stages in my account. It is mentioned above that, as in the all types of beauty, at first sight or hearing a pleasure is felt towards the artwork, which attracts the perceiver with the harmony and balance in itself and its elements. While the perception of the work is proceeding, the viewer or listener examines the details in the piece of art. In the process of perceiving both painting and music, the perceiver

\footnotetext{
${ }_{4}$ The ideas in the entire paragraph can be regarded as a combination of the ideas mentioned by Hanslick (1891) and Kivy (2002) about programmed music.
} 
Çoraklı, E. (2014). On the beauty of nature, paintings and music. International Journal of Human Sciences, 11(2), $297-313$. doi: $\underline{10.14687 / \text { ijhs.v11i2.2900 }}$

recognizes how the artist has used the artistic elements skillfully and has brought a product to the world possessing a pure beauty, in painting by combining the technic integrity with his original touch of brush and revealing a unique image, and in music by gathering independent tones in such a manner that they capture the audience with their order, flow and dynamic changes. At his point, the pleasure transfers into the feeling of appreciation towards the creator's ability to bring this pure beauty into world. The beauty of nature belongs to the mysterious huge power of the nature itself, but the beauty of arts is produced by something it has created. This is such a talent and the result is such a beauty that, it exceeds the strength of the nature, which rules the world, defies its power and proves the human intellectual strength to create something as pure as its products.

While the appreciation changes its direction towards peace, lot of variations of ideas flow into the mind of the perceiver. At this point, let's distinguish painting and music for one more time, because even if both of their judgments have same stages, they have got distinctive features making them to reach the feeling of peace. After this short elaboration process, we will reach a general conclusion.

Paintings represent a frozen segment of life, as distinct from the real life and humans, which are rather active. This everlasting energy, combining with the impure ambitions about life prevents us to see things that we look at. Hence, the motionless moment paintings are reflecting, whether a beautiful landscape or just an ordinary scene, exhibits what we are missing in the hastiness of life: The hidden aesthetic details that we don't bother to pay attention. The touch of the artist produces not only a new and beautiful physical object, but also a kind of miracle, which causes perceiver to realize the visual details the artist is aware of and is emphasizing. The artist sometimes draws an ordinary scene with his own interpretation and achieves to convert it something beautiful. His seeing what is behind the ordinary scenes contributes the perceiver's perspective towards the visual elements in life. This may seem as if it is such a complex whole of feelings ideas, which reaches us to the feeling of peace, but it is not. However, it is also a fact that it does not happen easily. It happens when the whole attention without impure ideas is directed towards the work of painting and its sheer beauty is both perceived and internalized. After we read psychology, we become more conscious about the reason of our and other people's behaviors. Similarly, when we realize the inner beauty of things in life with its all dimensions, our perception on all the visual elements of life becomes more deliberative and we are closer to the final feeling peace. Thus, after the experience of a painting with all the stages completed, the life is never same for the perceiver.

Music, unlike painting, reflects the active side of life. It is a process just like the life itself and the human life, with a beginning, development and end. The listener experiences a small 
Çorakl1, E. (2014). On the beauty of nature, paintings and music. International Journal of Human Sciences, 11(2), $297-313$. doi: $10.14687 /$ ijhs.v11i2.2900

process of life, while the music is flowing with its changing dynamics. ${ }^{5}$ The music, just like him, is born (beginning), grows up (development) and dies (end). It rests, repeats and even has feelings. But this model of life is also different from the real life. It makes all these actions in a harmony and care. It is so refined and elegant that its even becoming angry or passionate is aesthetically expressed and is away from the unsuitable words and behaviors. Moreover, the vibrations spreading over do not only penetrate the ears but also the whole body, and therefore make this experience happen deeper inside. The soul of the humans, then reach the peace in this beautifully flowing tones. He experiences all the stages of life in just minutes and finds the ideal of pure life in it. The effect of music, just like in the case of paintings, creates a kind of magic in the human's soul and life, if it is perceived with all its stages.

The final peace, which is reached at the final stage of the aesthetic judgments of both painting and music, also includes the feeling of eternity, like in the judgment of the natural beauty. The moments and the flow of life are eternalized in the surface of the canvas and the performance of the musical piece. The perception ends but the works of art will always be there (at least the idea of them will remain even if they are destroyed from the physical world), and there will be always new beautiful works depicting a frozen moment or reflecting of the flow of this circle. All this process, including of the usage of feelings, ideas and imagination, generates the judgment of the beauty of arts, or in other alternative words, 'the artistic feeling of beauty'.

\section{Conclusion and Further Ideas}

After a long process of analyzing, I have come to a point that the ideal aesthetic judgment of the nature, paintings and music ends with the feeling of peace, which takes its roots from the feeling of eternity. But, how can a merely beautiful thing cause this deep feeling? And, why not everyone reach to this point in the aesthetic judgment?

I think the answer for the former question lies on the sheer pleasure felt in the beginning of this judgment. That kind of pleasure can be only felt towards a sheer entity. It is a kind of matching. Hence, as I mentioned in the previous chapters, people feel this pure delight in a natural receptivity, without the desire or ambition to possess it. On the contrary of the pureness of the beautiful entity and felt delight towards it, humans and the environment have lost their pureness in some aspects. They are full of profane desires and ambitions, and the environment is full of artificial and unaesthetic objects they have created, as the result of the empirical world they are living in. Why have humans lost their pureness? The answer is in the intelligence, which is the main source of the

\footnotetext{
5 This idea has taken its roots from Schopenhauer's ideas about music in 'The World as Will and Representation'. He considers music as representing the will, which is the major metaphysical force constituting the inner nature of the phenomena and mankind.
} 
Çoraklı, E. (2014). On the beauty of nature, paintings and music. International Journal of Human Sciences, 11(2), $297-313$. doi: $10.14687 /$ ijhs.v11i2.2900

empirical world and its rules. While contributing to the civilization, intellectual capacities have also given harm to humans. It has prevented the humans from internalizing the essence of life. This essence is hidden in the feeling of eternity, which points at another innate feeling of being part of this endless circle, though as an individual, he will die. This truth is valid for every living entity: Even if all creatures of the nature pass away, the circle of life is eternal. When we look at flowers, which are lack of intellectual capacities and unaware of the empirical world, we realize that they are in such a calm receptivity. However humans are not, and instead, they defy the pure reality of life and struggle between this universal truth and his expectation to live forever as an individual. Their restlessness and ambitious actions take their origin from the feeling that they have to survive through the life. However, all they need is, to feel the essence of life in a calm receptivity and face with the truth that living is just contributing this circle.

By an irony of this chaos in the human soul, the beauties are there, to be recognized, felt and internalized. They don't exist to give a mere feeling of pleasure, but more to the point, to remind humans the pure truth of life that they are missing while engaging with living. When humans encounter a beauty of nature, the immediate pure pleasure will direct them to the deep ideas and feelings about the circle of life, universe and their existence. When they see a beautiful painting, the sheer delight will be followed by the recognizing of details of images in the frozen scene, which brings the awareness of the eternal beauty of the moments. After a pleasing work of music is listened, the eternal flow of the nature with the energy of the humans will be felt inside. At the end, they will come to the final idea that the beauty itself, as a pure concept giving a pure delight, is eternal: a flower will always be beautiful as the world continues to revolve, likewise Van Gogh's 'Starry Night' and Korsakov's 'Scheherazade'. All these feelings and ideas will come together in the common feeling of peace.

In the first paragraph of this chapter, I had asked another question: Why doesn't the beauty usually arouse these deep feelings and ideas after its judgment? Actually, there are even times that people pass by or ignore beauties without recognizing them.

As I mentioned in the previous chapters, the impureness of human mind full of profane ideas, desires and ambitions blocks him to be aware of the beauties and complete all the stages to reach the final deep feeling of peace. A pure mind, which every one possesses by birth, requires effort to be gained back. The intellect of the humans, which is the main reason for impure ideas yet also the source for thinking and creating works of art should be educated in such a way to keep or gain this pureness. Hence, we should overview and modify all our educational system, which only serves for practical aims of life. The first step for this aim is to prepare a ground for more involvement with aesthetic experiences of every kind. Thus, the beauty itself can be a great teacher 
Çoraklı, E. (2014). On the beauty of nature, paintings and music. International Journal of Human Sciences, 11(2), $297-313$. doi: $10.14687 /$ ijhs.v11i2.2900

to make people aware of from what their minds should be refined and with what it feeds well. Humans, who are the only creatures possessing the intellect to discuss and create beauty, should learn how to use their intellect towards deeper aims. That would be a great contribution to what humanity have lost so far.

For further studies, all types of beauty need to be independently and profoundly analyzed. The more we think of beauty, the more we can find a way to explore its value, and use it for the development of humanity.

\section{References}

Aristotle. The Politics of Aristotle, translated by E. Barker, London: Oxford University Press.

Budd, M. (1995). Values of Art, London: Penguin Books.

Hanslick, E. (1891). On the Musically Beautiful, translated by G. Payzant, Indiana: Hackett Publishing Company

Kant, I. (1790). Critique of Judgment, translated by J. C. Meredith, New York: Oxford University Press.

Kivy, P. (2002). Introduction to a Philosophy of Music, New York: Oxford University Press.

Leibniz, G. W. (1700). 'On Wisdom' from Philosophical Letters and Papers. Translated and Edited by Leroy E. Loemker. Chicago: Chicage University Press, 1956.

Lessing, G.E. (1853). Laocoon 'An Essay on the Limits of Painting and Poetry', London: Johns Hopkins University Press.

Peacocke, C. (2009). “The Perception of Music: Sources of Significance”, British Journal of Aesthetics, 49:3, pp. 257-275.

Plato. The Republic of Plato, translated by F. M. Cornford, London: Oxford University Press.

Schopenhauer, A. (1819). The World As Will and Representation, translated by E. F. J. Payne, Colorado: The Falcon's Wing Press.

Scruton, R. (1997). The Aesthetics of Music, New York: Oxford University Press. 